\title{
New Perspectives on Sustainable Business (Editorial)
}

\author{
Paul Burger \\ Claus-Heinrich Daub \\ Yvonne M. Scherrer
}

The debate regarding sustainability in business and the economy has been ongoing for several decades. Initially focused on general concerns regarding economic growth (e.g. ecological economics), the debate has not only gained strong momentum and diffused in different scientific fields working on business and economics, but has also reached the realm of applied business itself.

In 1992, a remarkable number of business representatives attended the UN conference on Environment and Development in Rio and discussed the contribution of business towards sustainable devel-

\footnotetext{
Paul Burger is head of the Program Sustainability Research within the Department for Social Sciences and Philosophy at the University of Basel and professor for the socio-cultural domain within the interdisciplinary Master Program in Sustainable Development. Initially trained as a Philosopher, his research interests focus on fundamentals for sustainability, values within sustainability issues, human-nature relations and instruments to scientifically investigate the future.

Claus-Heinrich Daub is Director of the Centre of Sustainable Management at the University of Applied Sciences Northwestern Switzerland. He heads the International Network for Sustainable Management (IfSM) and is the current president of the Society for Scientific Publishing in Switzerland. Previous publications include contributions to sustainable management, economic sociology, strategic marketing and communication.

Yvonne M. Scherrer is project manager in sustainability-related research projects at the University of Applied Sciences Northwestern Switzerland, School of Business, and organiser of the First and Second International Sustainability Conferences ISC 2005 and ISC 2008 in Basel. Her current research activities focus on stakeholder interactions in the context of (natural) resource management. Yvonne $M$. Scherrer is a PhD student at the University of Basel and currently vice president of the Society for Scientific Publishing in Switzerland.
}

opment. The outcome of their debates was published in "Changing Course", edited by the Swiss entrepreneur Stephan Schmidheiny together with the Business Council for Sustainable Development (today World Business Council for Sustainable Development, WBCSD). More recently, initiatives and instruments, which include the well known Global Reporting Initiative (GRI) and Global Compact, have been developed to institutionally involve business in the world's most challenging endeavour: transforming human societies into sustainable societies.

Notwithstanding the growing public awareness of the need for a sustainable economy, global challenges such as population growth, poverty, public health, sanitation and drinking water availability, global warming, overfishing, pressure on biodiversity, degradation of soil and reduction of fertile land for agriculture - in general, overall scarcity of ecological resources - still remain unresolved issues and point away from a more sustainable global human society. All of these issues indicate that we still have a long way to go to achieve a sustainable economy.

There are many reasons for ongoing nonsustainability. One is a lack of conceptual clarity regarding the link between sustainability and business. Sustainability in a broader context addresses macro-societal concerns and may be understood as being oriented on common goods. It is then one thing to operationalise sustainability on the theoretical background of economics, e.g. to model political and financial instruments as macroeconomic phenomena. Business decisions, however, are based on individual interests of the businesses or market players directly involved. Although there are serious objections to a pure neo-liberal approach to 
business, individual interests play an important role within the context of a market economy. The crucial question is: To what extent is it possible to include sustainability concerns within a business framework which serves individual interests?

Moreover, there are conceptual difficulties regarding the basic constituents of sustainability. For example, inter- and intra-generational justice: Do we assess the practical consequences of our actions on the basis of an egalitarian or non-egalitarian approach? Do we believe that we can develop criteria for just actions and base them on human preferences alone, or is it necessary to consider stronger constraints, such as the capability approach developed by Sen and Nussbaum? Depending on one's concept of justice, one will arrive at very different conclusions. In case the pure neoliberal principle should be right, sustainability might be considered nothing new, conceptually reducible to efficiency plus a utilitarian approach to justice. As a consequence, there would be little room for proposals such as Corporate Social Responsibility (CSR), Corporate Citizenship or Corporate Sustainability, all addressing business' responsibilities to society.

If, however, this reductive approach is not viable - and there are many good reasons to be critical of such an approach - then we truly need to conceptually translate the chosen universal normative rules (values, duties or whatever category might fit best) into the realm of business. A social scientist might be tempted to say that in order for the societal role model called "sustainability» to become a useful normative guide for business, it has to be adapted to the societal subsystem 'economy' in a way that individual interests of the market players become framed by sustainability concerns. Although this statement may appear to be supported by strong evidence, its theoretical clarification and practical application remain a difficult challenge.

The papers presented in this special issue of "Journal of Business Ethics" contribute to the general task of operationalising sustainability for business in different ways. Hanke/Stark, Sachs/Maurer and Kleine/von Hauff explicitly address the tension between the individual good and the common good and present tools for adapting sustainability to business strategy. Like Bilgin, the authors of these papers rely on the concept of CSR or that of business having a social and ecological environment for developing concepts of Corporate Sustainability (term used by Kleine/von Hauff). One of the issues which arises from this discussion is "the deep-rooted values and beliefs within organizations which are responsible for the acceptance (and non-acceptance) of an organizational engagement" (Hanke/Stark). Scherrer's paper gives an interesting insight exactly on this type of value concerns. She analyses the value shift within three internationally operating environmental NGOs, hence three important partners (or adversaries) for business acting on a wide number of important sustainability issues. Additionally, Daub/Scherrer addresses another problem for business where it does not suffice to be environment friendly or action committed (terms suggested by Bilgin). The management of a firm needs to understand its societal environment and with whom a corporate citizenship project can be implemented. How "the right thing" might be effectively implemented is analysed on the basis of a case study.

Another line of reasoning is expressed in Krysiak's and Som/Hilty/Köhler's papers. Focusing on conceptualising sustainability for the economic domain, they link together tools stemming from risk analysis and sustainability. Krysiak argues not only for "limiting the probability of harming future generations" as an ethically tenable concept of sustainability (fairness approach), but also for it being a fertile framework to link known risk management tools to sustainability oriented planning and decision making. Som/Hilty/Köhler suggest to extend the analysis of risks induced by technological innovation such as information technology to the social domain and to apply the precautionary principle as a tool to adapt the general notion of sustainability to relevant concerns towards a sustainable information society.

In terms of methods Krysiak's paper links normative arguments with economic modelling. Scherrer's and Daub/Scherrer's papers use sociological tools in order to analyse both the mentioned "value shift" and the social environment as a precondition for "right" actions. Within the group of papers which use CSR as a starting point, a wide variety of scientific tools are applied, including management, marketing, stakeholder and organisation theories. These papers often combine normative arguments with empirical research. Rather than offering all encompassing 
solutions, the papers provide an overview of a variety of different scientific approaches to "sustainable business".

Most of these papers were initially presented for the first time at the First International Sustainability Conference held in October 2005 in Basel, Switzerland. The conference focused on the interface between social and economic aspects of Sustainable Development in general and in particular on strategies towards sustainable development. We would like to thank the contributing authors, our reviewers and conference advisors, and the editors of JOBE for accepting this sample of papers to be published as a special issue.
Paul Burger Program Sustainability Research, University of Basel, Klingelbergstrasse 50, 4056 Basel, Switzerland E-mail:paul.burger@unibas.ch Claus-Heinrich Daub and Yvonne M. Scherrer School of Business, University of Applied Sciences Northwestern Switzerland, Zuercherstrasse 1202, 5210 Windisch, Switzerland E-mail: clausheinrich.daub@fhnw.ch; yvonne.scherrer@fhnw.ch 